in press The American Journal of Psychology

Running head: The end

\title{
The End of Overconfidence
}

\author{
Review of 'Perfectly confident: \\ How to calibrate your decisions wisely' \\ by Don A. Moore \\ Joachim I. Krueger \\ Brown University \\ Patrick R. Heck \\ Geisinger Health System \\ 2,805 words of text \\ (excluding references)
}

\section{Correspondence:}

Joachim I. Krueger

Department of Cognitive, Linguistic \& Psychological Sciences

Brown University

190 Thayer St.

Providence, RI 02912

Phone: (401) 863-2503

Home page: http://research.brown.edu/research/profile.php?id=10378

Keywords: overconfidence, confidence, judgment and decision making, cognition, rationality

Note: This book is published by HarperCollins, New York, NY, 2020.

ISBN 978-0-06-288775-7, list price \$29.99 
"Most people are overconfident about the benefits of overconfidence."

- Moore (2020, p. 202)

William James (1874/1978), ever the pragmatist, imagined himself hiking in the Alps and being stuck in a hard place. The only way out is to take a bold leap across a crevasse. James figured it is best to believe in one's athletic prowess as confidence would make success more likely. Belief would beget truth. Writing from Massachusetts and not the Matterhorn, James settled for a thought experiment, capitalizing on his own (and the readers') willingness to believe in belief. James thereby ennobled a tenet of folk psychology which states that you can do (almost) anything if you put your mind to it. Social psychology, and especially Shelley Taylor's work on positive illusions (Taylor \& Brown, 1988) has boosted the idea that positive mental states are not only their own reward, but that they can bend reality in desired directions. The positive psychology movement has produced an additional spate of studies on the presumed benefits of optimism (Seligman, 2006). In research on business and entrepreneurship, a parallel literature extolls the virtues of daring and risk-seeking leadership (Dess \& Lumpkin, 2005). The self-help industry has broadcast these uplifting claims for obvious reasons.

The advent of behavioral decision theory brought challenges to the Jamesian pragmatism. Research on quantitative judgment, decision-making, and risk-taking began to understand the dangers of overconfidence (Fischhoff, Slovic, \& Lichtenstein, 1977). A host of cognitive limitations, sampling biases, and intuitive shortcuts, in combination with motivated and egocentric tendencies, corrupt human judgment, with the result that people tend to see themselves, their capabilities, and their outcomes in a more positive light than the evidence justifies. Some have concluded that overconfidence is the gateway bias of the bounded mind, enabling further errors and irrationalities (Kahneman, 2011). Overconfidence is the original sin of self-consciousness. What does this mean for James's claim that overconfidence can be salutary? Might overconfident beliefs be self-nullifying; do they take the 'over' out of overconfidence? 
The time is ripe for a good review of overconfidence and its consequences. With 'Perfectly Confident,' Don Moore, a psychology professor at the Haas School of Business at the University of California, Berkeley, has provided such a review. For over two decades, Moore has plumbed the theoretical and empirical questions of confidence in an influential research program. Now he presents three conclusions. First, there is no single type of overconfidence, but a family of related phenomena. Second, James was overconfident about confidence because he failed to understand the power of reality to trump desire. Third, there is no single recipe to mitigate overconfidence, but a family of heuristic interventions.

\section{Multiple confidences}

The distinction between overestimation, overplacement, and overprecision as separable forms of overconfidence is central to Moore's theory (Moore \& Healy, 2008). Overestimation is shown by a positive difference between self-assessment and an objective measure, such as a test score, overplacement by a positive difference between self-assessment and assessments of others, such as the average person, and overprecision by a positive difference between a subjective and an objective confidence interval bracketing a point judgment. The first two differences are related because they both depend on self-assessments. Across respondents, higher self-assessments will correlate positively with both larger estimation and placement errors, and therefore, there will be correlations between these two types of errors (Krueger \& Wright, 2011). Moore has shown, however, that this latter correlation is negative when the task difficulty enters as a moderator variable. Simple regression ensures that performance is likely overestimated for difficult tasks and underestimated for easy tasks. Critically, differential regression means that when assessments of others are more regressive with respect to true scores than self-assessments are, respondents will overestimate the performance of others even more than their own performance on difficult tasks and underestimate the performance of others even more than their own performance on easy tasks.

To show these regularities in stylized form, we created 5,000 simulated cases where we set the mean to 50 and the standard deviation to 15 for each of the three variables of S (the case's 
estimate of own score, 'Self'), T (true score, 'True'), and O (the case's estimate of the average other's score, 'Other'). In this trivariate simulation, the three pairwise correlations were the following: $r \mathrm{SO}=$ $.4, r \mathrm{ST}=55$, and $r \mathrm{OT}=.2$. These correlations designate - in the order listed - social projection (i.e., the perceived self-other similarity), the accuracy of self-estimates, and the accuracy of otherestimates. All three correlations can be assumed to be positive on theoretical grounds, although their observed values will depend on the task, the context, and the vagaries of sampling. It may also be assumed that self-estimates are less regressive with regard to true scores than are other-estimates (i.e., $r \mathrm{ST}>r \mathrm{OT}$; Krueger, Freestone, \& MacInnis, 2013). In our simulation, the correlation between $\mathrm{S}-\mathrm{T}$ (overestimation) and $\mathrm{S}-\mathrm{O}$ (overplacement) is +.25 when computed over all cases, but it is -.98 when $\mathrm{S}$ and $\mathrm{O}$ are first averaged at each level of $\mathrm{T}$. Figure 1 shows that our replication resembles the typical outcome seen in a study conducted in Moore's paradigm. In the figure, the regression lines for S on T and for $\mathrm{O}$ on $\mathrm{T}$ are estimated from the simulated data. The figure clearly shows how overestimation and overplacement respectively become smaller and larger as tasks become easier, that is, as true scores increase.

Beyond the narrow settings of simulations or judgment experiments, overestimation or overplacement are critically associated with success and failure. For leaping James, an accurate assessment of his long-jump ability is decisive, whereas for people engaged in social dilemmas, such as entrepreneurs considering market entry, an accurate assessment of others' capabilities is crucial as well. In such contexts, it may be advantageous to integrate estimation and placement data into a decision matrix displaying whether those who think they are better than average actually are, and whether those who think they are below average actually are. This approach separates warranted high confidence from a confidence error (Heck \& Krueger, 2015). Using the data from the simulation, Figure 2 shows this classification scheme.

Overprecision is the least intuitive type of overconfidence. People do not routinely say, 'Here is my estimate of quantity X. I could be wrong. I think there is a $90 \%$ chance the actual quantity lies 
in a range bounded by my estimate plus and minus Y percentage points.' Of course, researchers can ask respondents to construct estimates displaying the degree of their uncertainty and show that the respondents are being overprecise. Moore shows that people can be trained to draw up histograms, and that such training improves understanding and reduces overprecision. Overprecision matters because people dislike uncertainty in general (Krueger \& Grüning, in press), but also because they feel that others expect them to express point estimates with precision (Stavrova \& Evans, 2018). This issue can be mitigated by saying 'I think there is a $60 \%$ chance for $\mathrm{X}$ to occur, and that there is a $90 \%$ chance that the actual probability lies between 50\% and 70\%, and I am 95\% sure about that.' Skilled communicators express high uncertainty with great certainty. Like overestimation and overplacement, overprecision is subject to regression effects. Moore notes that underprecision rarely occurs. The main reason for this is that high levels of precision command interest. When respondents are asked to lay a $90 \%$ subjective interval around their estimates, the corresponding objective intervals are likely wider. As subjective precision errors, like estimation and placement errors, emerge from statistical regression, $50 \%$ confidence interval will likely be too wide.

\section{The limits of pragmatism}

Moore recalls his participation in a Tony Robbins event and his collaboration with the master. Robbins stokes confidence in his acolytes by having them walk across a bed of burning embers (an old carnival trick). Most takers are underconfident at the outset but find pride and elevation when they complete the walk. Moore confesses that he burnt his soles because he failed to remove smoldering residue after the walk. This was a Jamesian moment of sorts, taking Moore beyond thought to experiment. But then again, there was no belief that created its own reality. The secret of the fire walk is that anyone can do it as long as they execute it properly. And this is Moore's point: a careful study of facts and evidence improves calibration. If confidence is too low at the outset, an increase in confidence will correlate with success.

Moore challenges the folk belief - shared and boosted by James - that higher confidence causes greater success, from which it would seem to follow that psyching oneself into a state of 
confidence will bring about success. Moore reminds readers of what they learned in freshman year: correlation is not sufficient for causation. If the correlation between confidence and success is positive, we must ask if there is a third variable causing both. Moore argues that actual ability is this variable. This common-cause model implies that interventions to increase confidence have no positive effect on performance and success. There is a chance of negative effects. Moore reports that overconfidence can backfire if it breeds complacency (e.g., Vancouver, More, \& Yoder, 2008). If people attribute their successes to their innate ability, they might conclude that effort is no longer necessary. On tasks that require both ability and effort, such discounting can be fatal.

In the sphere of the economy and business, there is a hard-dying belief that the secret sauce of success contains mental factors such as grit, resolve, charisma, and confidence. Some ingredients, such as charisma, seem to be - as the name suggests - a gift of the gods, about which nothing can be done. You either have it or you don't have it. Confidence, however, stirs the hope that something can be had for nothing. One only needs to put one's mind to it. Moore exposes this illusion as wishful thinking. This turn from pragmatism to realism has precedents. Years ago, the so-called self-esteem movement claimed that high self-esteem causes success and good citizenship behavior. Hence, we need programs to boost self-esteem, and all of society will be better for it. A task force of what was then called the American Psychological Society found low correlations between self-esteem and success, and the few reliable causal effects were due to third variables such as ability, or they ran from success to self-esteem (Baumeister, Campbell, Krueger, \& Vohs, 2003).

One compelling study comes from Moore's own laboratory (Tenney, Logg, \& Moore, 2015). Here, high confidence was experimentally induced as an expectation to receive a high score on a test. Optimists, it turned out, performed no better than pessimists, although other respondents, who only made predictions, thought that they would. If the pragmatic benefits of overconfidence are slim to none, there are palpable risks. Moore describes scenarios and research findings from settings of trading, competing, betting, and auctioning, among others. Consider day trading. Many traders think they can beat the market, which amounts to believing they can outsmart others who also think they 
can outsmart others. Day trading thus combines overestimation and overplacement (see top right quadrant in Figure 2). Moore's analysis implies that any trading entailing a cost and all parties valuing the payoffs in the same way (as opposed to trades involving an exchange of one commodity for a different one) is self-defeating. A host of psychological biases keep traders from seeing this. Moore notes that day traders not only play against one another, but also against highly paid Wall Street analysts and algorithms. If the analysts share the day traders' biases, one wonders if the algorithms do, or if the algorithms perform well, in part, because they are written to sucker the day traders.

By 'perfect confidence' Moore means confidence grounded in ability or evidence-based estimates. Having exposed the false promises of pragmatism, the question that remains is how such perfect confidence can be achieved. How may calibration supplant desire? The short answer is to reduce one's confidence, cultivate moderation, and follow the path of the Buddha, Socrates, or Maimonides - as Moore suggests in his epilogue. The long answer requires a review of a suite of specific techniques.

\section{Debiasing}

The wary person should ask to what extent an experienced level of confidence stems from poorly reflected hopes and fears. A cool head is in order. But the cool head needs some tools to calibrate confidence. The first step is to make self-assessment more regressive. If confidence is very high, it is probably too high; if it is very low, it is probably too low. Increased regressiveness will likely reduce estimation and placement errors. Or so it seems. Recall that the calibrator also knows whether she overplaced or underplaced, and whether the task feels easy or difficult. If the task is easy, confidence tends to be high but not high enough, and judgments about others tend to be too low. The judicious adjustment is to reduce overplacement by raising one's expectations about others. Conversely, when the task is difficult, confidence tends to be low but not low enough, and the judicious response is to lower expectations about others to reduce underplacement. The trick is to 
weigh the conflicting demands of moderating self-assessments when task difficulty is not known and making self- and other-assessments less regressive when task difficulty is known.

There are other approaches to calibration beyond the shifting of estimates within the statistical measurement model. Moore presents many useful techniques, scattered throughout the book (a table would have been welcome). The common denominator of these techniques is expansive (or 'extensional' in Kahneman's parlance) reasoning. Inspecting the credibility of their intuitive confidence levels, people can, and should, bring to mind what usually does not come to mind on its own. They can simulate alternative outcomes, the beliefs of others, confidence levels associated with disaggregated aspects of the task, and even self-challenging betting exercises. 'Premortems,' 'backcasting,' and the 'wisdom of the crowd' are part of the (useful) jargon here. Surveying a richer landscape of possibilities and considerations, calibrators can then re-aggregate the results and expect some improvement. Such exercises of simulation and integration come from a healthy attitude of skepticism with regard to intuitive and emotional experiences of confidence and an even healthier reorientation of attention from outcome to process. Integrated simulations, almost by definition, will be more regressive, that is, more moderate than snap confidence.

Moore's recommendations take a prescriptive tone when he extols the virtues of expectedvalue calculations. "Expected value is," Moore asserts, "what any sensible decision must be based on" (p. 122). What he advocates amounts to, for lack of a better phrase, pre-registered decisionmaking. Moore admires the role of the advocatus diaboli the Catholic church once institutionalized to protect itself from a surge of saints. We will play this role in order to note a limitation to the expected-value standard. Moore's discussion comes out of his review of business practices rewarding short-term successes and penalizing bolder initiatives gone bad, even though the risks had been calculated properly and considered acceptable. Such practices are counterproductive because they involve outcome bias (Baron \& Hershey, 1988). Moore, finding rationality in good calibration, argues that good decision-making under risk should be rewarded regardless of short-term outcomes, because over the long term, well-calibrated decisions outperform poorly calibrated decisions. Moore 
overlooks that calibration and risk are conceptually independent. A decision can be well-calibrated or poorly calibrated in high- and in low-risk endeavors. Good calibration is a necessary but not a sufficient ingredient of long-term value maximization.

\section{Conclusion}

Social psychologists and observers of the positive psychology movement will notice that Perfectly Confident is a long-awaited response to Shelley Taylor's (1989) Positive Illusions, a book that promised too much with too little evidence. Perfectly Confident is an excellent piece of scholarship and science writing. It will appeal to academics at all levels, businesspeople, and anyone interesting in improving their everyday decision-making. The writing style is engaging, and readers will forgive the author for shattering their free-lunch illusion regarding confidence. Once disillusioned, the readers find actionable guidance for what to do in order to become more (if not 'perfectly') calibrated.

William James deserves having the last word - addressed to him. James, your confidencefueled crossing of the crevasse is a poor thought experiment. Not having a choice but to jump, a practitioner of your 'subjective method' will mentally review the process of jumping, asking what kind of run-up is required, which rocks to step on and which to avoid, how to breathe, and then focus on optimal execution. These considerations are enough to fill a person's mind. Any other thoughts, like recalling what one had for breakfast should be banished. Thoughts about how confident one feels fall into that breakfast category. They are distractions. This conclusion extends to Moore's argument. Once the necessary mental work is done, thoughts about one's confidence are cognitive ballast. It is time to get on with the task. 


\section{References}

Baron, J., \& Hershey, J. C. (1988). Outcome bias in decision evaluation. Journal of Personality and Social Psychology, 54, 569-579. doi: 10.1037//0022-3514.54.4.569.

Baumeister, R. F., Campbell, J., Krueger, J. I., \& Vohs, K. (2003). Does high self-esteem cause better performance, interpersonal success, happiness, or healthier lifestyles? Psychological Science in the Public Interest, 4, 1-44. doi: 10.1111/1529-1006.01431

Dess, G. G., \& Lumpkin, G. T. (2005). The role of entrepreneurial orientation in stimulating effective corporate entrepreneurship. Academy of Management Perspectives, 19(1), 147-156. https://doi.org/10.5465/ame.2005.15841975

Fischhoff, B., Slovic, P., \& Lichtenstein, S. (1977). Knowing with certainty: The appropriateness of extreme confidence. Journal of Experimental Psychology: Human Perception and Performance, 3(4), 552-564. https://doi.org/10.1037/0096-1523.3.4.552

Heck, P. R., \& Krueger, J. I. (2015). Self-enhancement diminished. Journal of Experimental Psychology: General, 144, 1003-1020. http://dx.doi.org/10.1037/xge0000105

James, W. (1874/1978). Some reflections on the subjective method. In Essays on philosophy: The works of William James. Harvard University Press.

Kahneman, D. (2011). Thinking, fast and slow. Farrar, Straus and Giroux.

Krueger, J. I., Freestone, D., \& MacInnis, M. L. (2013). Comparisons in research and reasoning: Toward an integrative theory of social induction. New Ideas in Psychology, 31, 73-86.

Krueger, J. I., \& Grüning, D. J. (in press). Psychological perversities of populism. In J. P. Forgas, \& K. Fiedler. The social psychology of populism [The 22nd Sydney Symposium on Social Psychology]. Taylor \& Francis.

Krueger, J. I., \& Wright, J. C. (2011). Measurement of self-enhancement (and self-protection). In M. D. Alicke \& C. Sedikides (Eds.), Handbook of self-enhancement and self-protection (pp. $472-$ 494). Guilford. 
Moore, D. A., \& Healy, P. J. (2008). The trouble with overconfidence. Psychological Review, 115(2), 502-517. https://doi.org/10.1037/0033-295X.115.2.502

Seligman, M. E. P. (2006). Learned optimism. Vintage Books.

Stavrova, O., \& Evans, A. M. (2018). Examining the trade-off between confidence and optimism in future forecasts. Journal of Behavioral Decision Making, 32(1), 3-14.

Taylor, S. E. (1989). Positive illusions: Creative self-deception and the healthy mind. Basic Books.

Taylor, S. E., \& Brown, J. D. (1988). Illusion and well-being: A social psychological perspective on mental health. Psychological Bulletin, 103(2), 193-210.

Tenney, E. R., Logg, J. M., \& Moore, D. A. (2015). (Too) optimistic about optimism: The belief that optimism improves performance. Journal of Personality and Social Psychology, 108(3), 377399.

Vancouver, J. B., More, K. M., \& Yoder, R. J. (2008). Self-efficacy and resource allocation: Support for a nonmonotonic, discontinuous model. Journal of Applied Psychology, 93(1), 35-47. 
Figure 1. The associations between ease of task (T), self-estimates $(\mathrm{S})$, and other-estimates $(\mathrm{O})$ and their resulting - inversely related - variants of overconfidence.

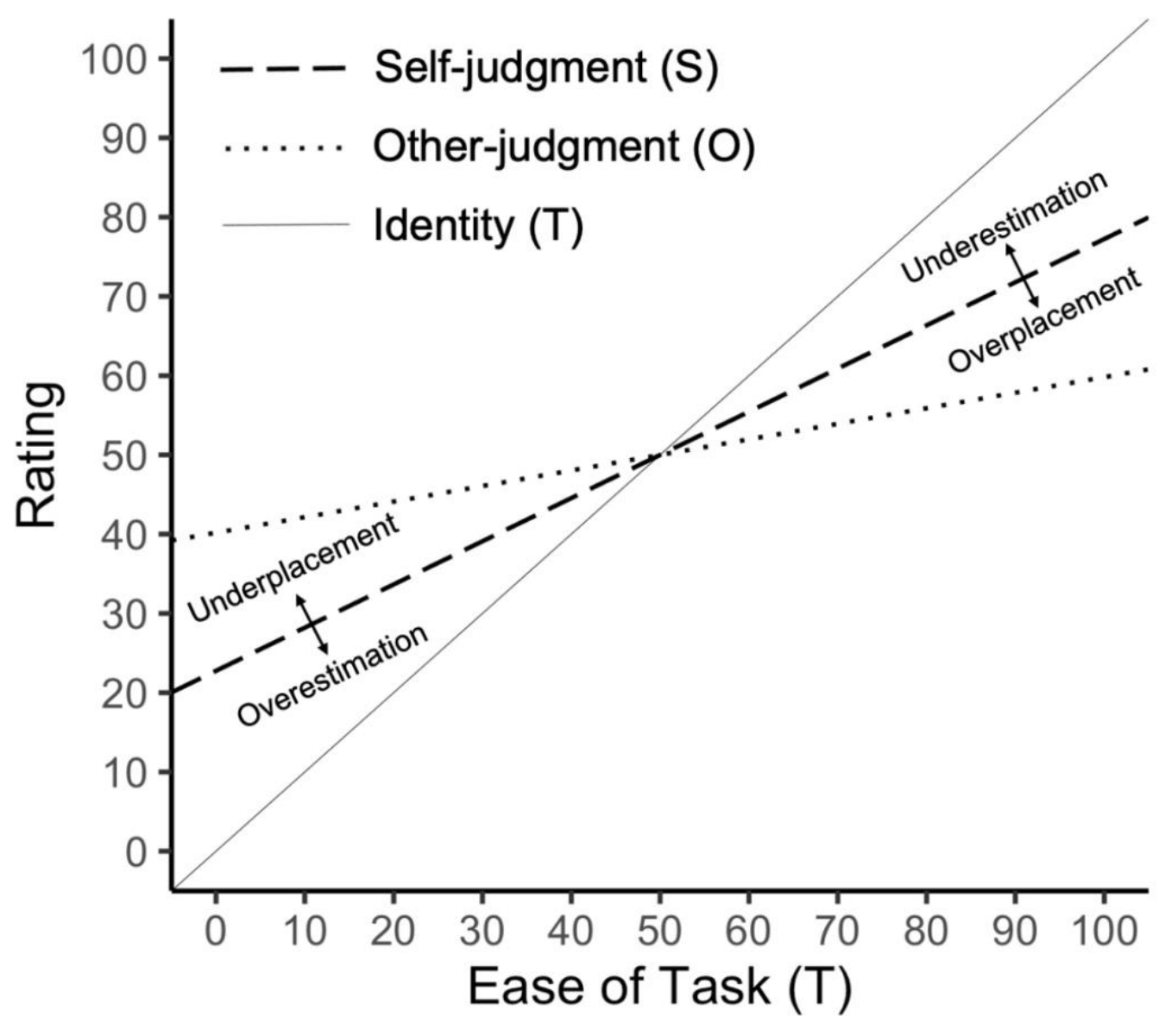


Figure 2. Classification of over- (under-)placement crossed with over- (under-)estimation. Inaccurate overplacers are those who commit overconfidence errors.

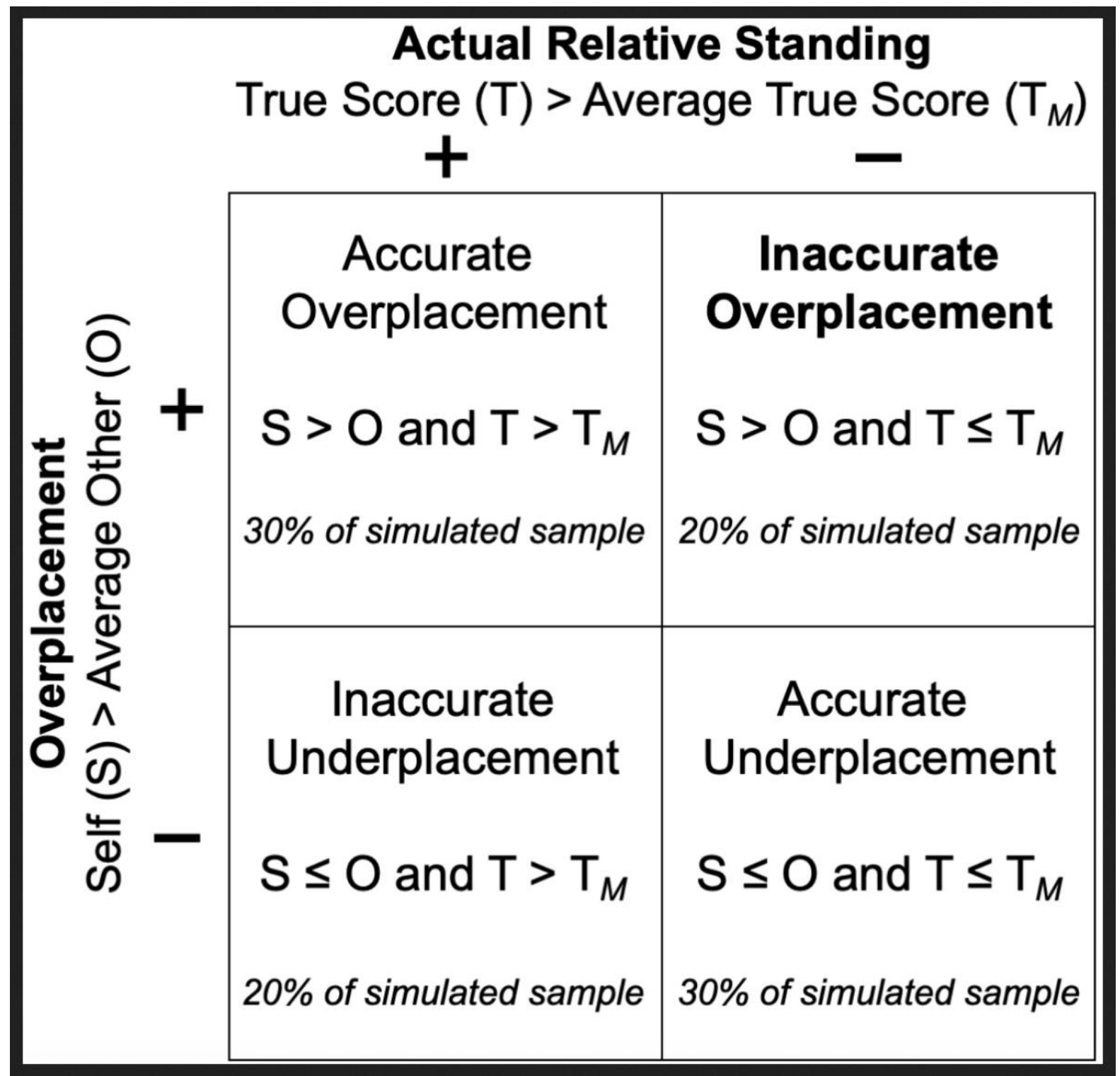

